\title{
Mechanism of Arsine Adsorption on the Gallium-Rich GaAs(001)-(4 × 2) Surface
}

\author{
Qiang Fu, ${ }^{\dagger}$ Lian Li,${ }^{\ddagger}$ Connie H. Li, ${ }^{\dagger}$ Michael J. Begarney, ${ }^{\dagger}$ Daniel C. Law, ${ }^{\dagger}$ and \\ Robert F. Hicks*,†
}

Chemical Engineering Department, University of California, Los Angeles, California 90095-1592, and Department of Physics and Laboratory for Surface Study, University of Wisconsin, Milwaukee, Wisconsin 53201

Received: February 14, 2000; In Final Form: April 6, 2000

\begin{abstract}
The kinetics and mechanism of arsine adsorption on the $(4 \times 2)$ surface of gallium arsenide $(001)$ has been studied by scanning tunneling microscopy, infrared spectroscopy, and ab initio quantum chemistry calculations. Arsine forms a dative bond to a gallium dimer. Then, this species either desorbs from the surface or decomposes to an $\mathrm{AsH}_{2}$ or $\mathrm{AsH}$ fragment with hydrogen transfer to an arsenic site. Finally, desorption of hydrogen leaves arsenic dimers on the surface. The energy barriers for arsine desorption and dissociation into AsH $\mathrm{H}_{2}$ are estimated to be 9.3 and $16.5 \mathrm{kcal} / \mathrm{mol}$, respectively. Gallium hydride is not produced upon dissociation of $\mathrm{AsH}_{3}$ because this process is not energetically favorable.
\end{abstract}

\section{Introduction}

Compound semiconductor devices have found many applications in the fast-growing telecommunications industry, including uses as fiber-optic transceivers, broadband cable modems, and satellite photovoltaics. The active layers in these devices are grown on the (001) plane of gallium arsenide by metalorganic vapor-phase epitaxy (MOVPE). ${ }^{1-10}$ In this process, volatile precursors of the group III and group V elements in a hydrogen carrier gas are fed into a reactor containing a substrate heated to between 773 and $923 \mathrm{~K}^{1-3}$ The precursors adsorb and decompose on the wafer surface, depositing a single-crystal film that is lattice-matched to the GaAs substrate. The film surface plays a crucial role in this process, because it mediates the decomposition of the group III and group V reagents. ${ }^{4-13}$ It is essential to understand the heterogeneous decomposition reactions because they affect the growth rate, film composition, film morphology, and dopant profiles, all of which impact device performance.

Arsine is widely used as the group V source during MOVPE, and its adsorption on $\mathrm{GaAs}(001)$ surfaces has been studied by several groups. ${ }^{14-17}$ Arsine undergoes dissociative adsorption at temperatures as low as $140 \mathrm{~K}$. Upon an increase in the substrate temperature from 140 to $450 \mathrm{~K}$, most of the arsine desorbs from the surface, while a small fraction decomposes to form arsenic dimers. White and co-workers ${ }^{15,16}$ found that the hydrogen from arsine transfers to As and Ga sites, generating both $\mathrm{As}-\mathrm{H}$ and $\mathrm{Ga}-\mathrm{H}$ stretching vibrations, as shown in their high-resolution electron-energy-loss spectra. However, this point has been disputed by Qi et al., ${ }^{17}$ who observed only As-H vibrational bands by infrared spectroscopy following arsine dosing of $\mathrm{GaAs}(001)$. In addition to this discrepancy, there are several unresolved issues regarding the arsine adsorption mechanism. In particular, the adsorbed intermediates have not been identified, and except for estimates of the sticking coefficient, little information is available on the reaction kinetics.

* Author to whom correspondence should be addressed. E-mail: rhicks@ucla.edu. Fax: 310-206-4107.

$\dagger$ University of California.

$\doteqdot$ University of Wisconsin.
In this paper, we report on a study of arsine adsorption and decomposition on the $\mathrm{GaAs}(001)-(4 \times 2)$ reconstructed surface using scanning tunneling microscopy, internal-reflection infrared spectroscopy, and ab initio calculations with density functional theory. We have identified each of the reaction intermediates and, with the aid of theory, determined their relative stabilities on the semiconductor surface. In addition, a kinetic model for the dissociative adsorption of arsine is presented.

\section{Experimental and Theoretical Methods}

The samples were prepared by growing GaAs films, $0.5 \mu \mathrm{m}$ thick, on gallium arsenide (001) substrates in an MOVPE reactor. ${ }^{9}$ After growth, samples were transferred directly into an ultrahigh vacuum (UHV) chamber with a base pressure of $2.0 \times 10^{-10}$ torr. The GaAs(001) crystals were annealed at 793 $\mathrm{K}$ for $30 \mathrm{~min}$ to obtain a clean and well-ordered gallium-rich $(4 \times 2) / c(8 \times 2)$ reconstruction, as verified by low-energy electron diffraction. The surface composition was measured with an X-ray photoelectron spectrometer (PHI 5000), equipped with a hemispherical analyzer. Scanning tunneling micrographs were obtained at a sample bias of -2.0 to $-4.0 \mathrm{~V}$ and a tunneling current of $0.5 \mathrm{nA}^{3}$

Arsine was introduced into the chamber at $5 \times 10^{-7}$ torr through a precision leak valve. Dosing was continued for up to 65 min to ensure that a constant coverage was obtained. A series of spectra was collected before and during arsine adsorption at $8 \mathrm{~cm}^{-1}$ resolution and with co-addition of 1024 scans. These spectra were collected by multiple internal reflection through $\mathrm{GaAs}(001)$ crystals that were cut into trapezoids 10-mm-wide by $40-\mathrm{mm}$-long by $0.64-\mathrm{mm}$-thick with $45^{\circ}$ bevels at each end. Thirty-one reflections occurred off the front face of the crystals. The long axis of the crystals used in the experiments was parallel to the [110] direction. The reflectance spectra presented here were obtained by taking the ratio of the spectra recorded at saturation coverage to that recorded before dosing. During the arsine adsorption experiments, all of the filaments in the chamber were turned off. It was important to do this, because otherwise, the arsine molecule dissociated on the filament, causing $\mathrm{AsH}_{x}$ and $\mathrm{H}$ fragments to adsorb onto the surface and yield anomalous results. 


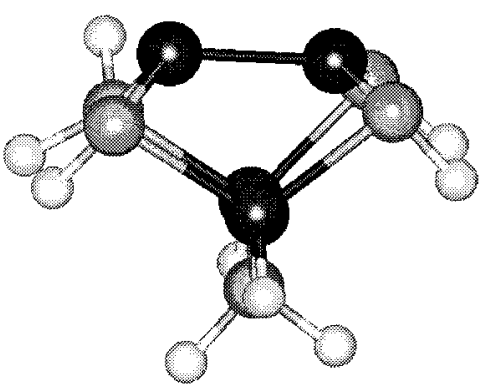

Figure 1. Ball-and-stick model of the $\mathrm{Ga}_{4} \mathrm{As}_{5} \mathrm{H}_{9}$ cluster used to simulate the gallium dimers present on the $(4 \times 2)$ reconstruction. The As, $\mathrm{Ga}$, and $\mathrm{H}$ atoms are the large gray, large black, and small white spheres, respectively.

Theoretical calculations were performed to identify the adsorbed intermediates and their energetics. The Ga-rich $(4 \times$ 2) surface was simulated using a $\mathrm{Ga}_{4} \mathrm{As}_{5} \mathrm{H}_{9}$ cluster, as shown in Figure 1. This cluster contains a single gallium dimer, which is the principal feature present on the $(4 \times 2)$ reconstruction (see below). Bonded to the dimer are the "bulk" arsenic and gallium atoms. These atoms are terminated with hydrogen to avoid spin and charge contamination from the truncated dangling bonds. The $\mathrm{Ga}-\mathrm{Ga}$ bond length calculated for the dimer is 2.60 $\AA$. This value is in good agreement with previous studies of the gallium-rich $\mathrm{GaAs}(001)$ reconstructions. ${ }^{18,19}$

Note that, in the $\mathrm{Ga}_{4} \mathrm{As}_{5} \mathrm{H}_{9}$ cluster, some of the bulk atoms are 3-fold coordinated, while others are 4-fold coordinated. This occurs because the number of nonbonding electrons is set equal to twice the number of 3-fold-coordinated arsenic atoms. Optimization of these clusters results in each As dangling bond being populated with a pair of electrons, while each Ga dangling bond remains empty. These dangling-bond configurations are consistent with the electronic properties of reconstructed $\mathrm{GaAs}(001)$ surfaces. ${ }^{20-22}$ If the number of nonbonding electrons is not chosen in the way just described, i.e., by not having the appropriate number of "bulk" hydrogen bonds, the cluster cannot be optimized.

$\mathrm{Ab}$ initio calculations using density functional theory were performed with the Gaussian 98 quantum chemistry suite. ${ }^{23}$ Perdew/Wang's gradient-corrected correlation functional and exchange functional (PW91PW91) were used throughout the calculations. ${ }^{24}$ For the Ga and As atoms, relativistic effects were considered by employing Stuttgart's electron-core pseudopotentials (SD-ECP) with a $(4 \mathrm{~s}, 4 \mathrm{p}) /[2 \mathrm{~s}, 2 \mathrm{p}]$ contracted basis set for the valence electrons. ${ }^{25,26}$ The Dunning-Huzinaga valence double- $\zeta$ basis set was used for hydrogen. ${ }^{27}$ This method has been successfully applied to the study of hydrogenterminated $\mathrm{GaAs}(001)$ surfaces. ${ }^{28}$

Calculations also have been performed on larger molecules that contain arsine or its decomposed fragments attached to $\mathrm{Ga}_{4}$ $\mathrm{As}_{5} \mathrm{H}_{9}$. All of these structures were fully optimized to their minimal energies, and no imaginary frequencies were found for the final states. The energies of the clusters were obtained from the PW91PW91/SD-ECP level calculations after accounting for the zero-point-energy correction. These results were also compared with those from a higher level of theory, i.e., PW91PW91/6-311G**//PW91PW91/SD-ECP. The average difference between these two sets of data was less than $\pm 1 \mathrm{kcal} /$ mol.

\section{Results}

3.1. Arsine Adsorption at 297 K. In Figure 2a, a filledstates STM image is presented of the clean $(4 \times 2)$ reconstruc-

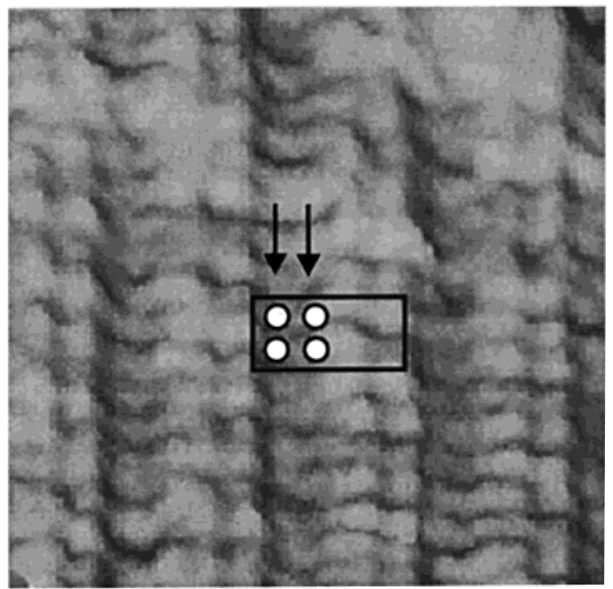

(a)

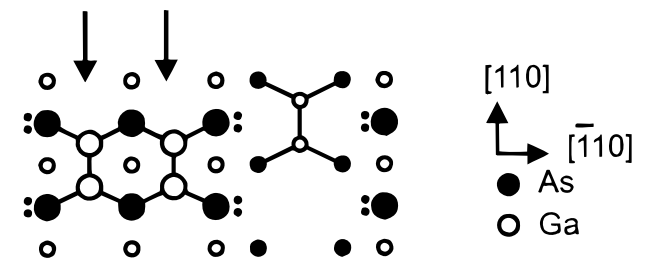

(b)

Figure 2. The $\operatorname{GaAs}(001)-(4 \times 2)$ reconstruction: (a) filled-states STM image, $60 \times 60 \AA^{2}$; and (b) ball-and-stick model.

tion. One sees a series of double rows of light gray spots that extend along the $[\overline{1} 10]$ direction. The distance between the double rows is $16 \AA$, giving rise to the $4 \times$ periodicity. Between the double rows are trenches, which are highlighted by two arrows in the figure. From a profile measurement, the average height corrugation between the trenches and the double rows is $0.6 \AA$, in agreement with previous work. ${ }^{29,30}$

The accepted structure for the $(4 \times 2)$ surface is shown in Figure $2 \mathrm{~b} .{ }^{3,29}$ Each unit cell contains three gallium dimers, two in the top layer and one in the third. In addition, there are four second-layer arsenic atoms with filled dangling bonds exposed along the edges of the trench. A $(4 \times 2)$ unit cell is highlighted by a rectangular box in the STM image (Figure 2a). The four white circles in the box represent the two Ga dimers in the top layer. Note that they are located within the trench. The double rows of gray spots in the micrograph are actually due to the lone pairs of electrons on the second-layer arsenic atoms. ${ }^{30}$

Shown in Figure 3a is an STM image taken after dosing the $(4 \times 2)$ surface with $1000 \mathrm{~L}$ of arsine $(1 \mathrm{~L}=1$ langmuir $=1$ $\times 10^{-6}$ torr $\bullet$ sec) at $297 \mathrm{~K}$. In addition to the double rows and trenches, the surface contains a few white mounds (four are present in the picture). These latter features are attributed to the adsorbed arsine. Based on counting the density of white mounds in six images, it was determined that the coverage equals $0.020 \pm 0.004 \mathrm{ML}\left[1.0 \mathrm{ML}=1.0 \mathrm{AsH}_{x}\right.$ species per $(1$ $\times 1$ ) unit cell].

In Figure 3a, arrows have been drawn on the micrograph to highlight the positions of the gallium dimers within the trenches. Close inspection of the picture reveals that the white mounds line up with the gallium dimers along the [110] direction. This result can be seen more clearly with the line scan drawn along the [110] axis (black bar in the figure). The line scan is presented in Figure $3 b$, and it reveals two trenches at points a and e 


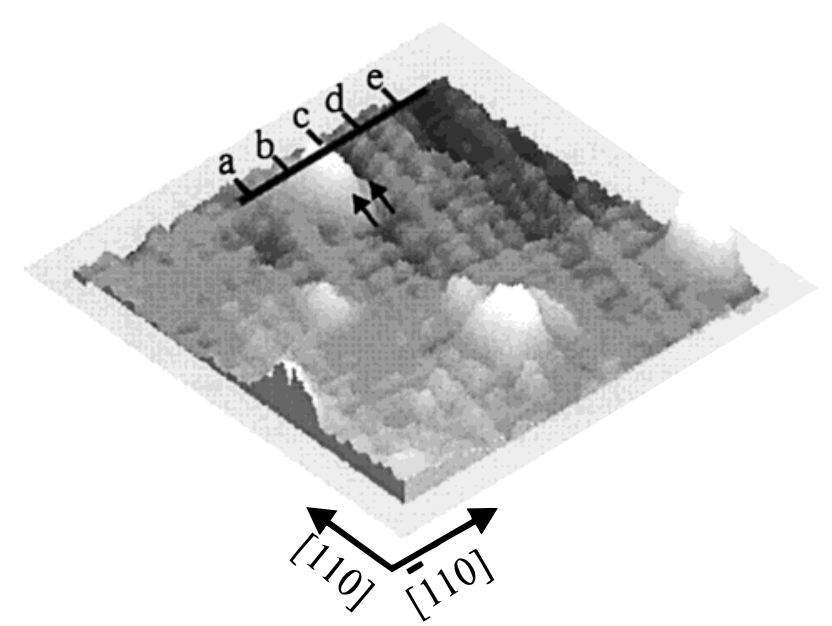

(a)

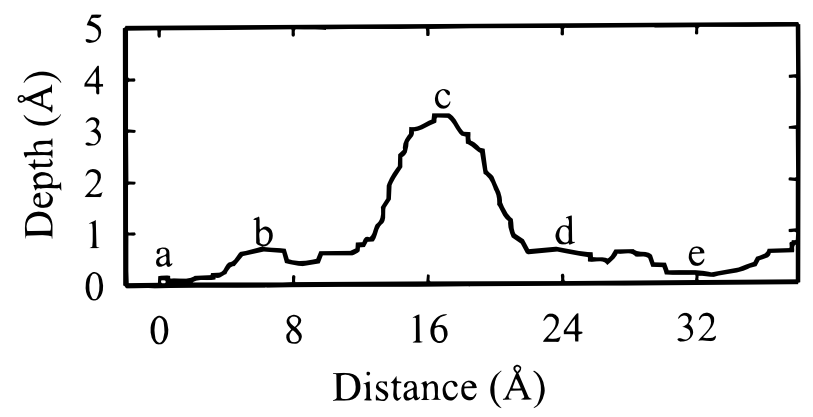

(b)

Figure 3. Adsorbed arsine on the $\mathrm{GaAs}(001)-(4 \times 2)$ reconstruction $\left(0.02 \mathrm{ML}\right.$ of $\mathrm{AsH}_{3}$ at $297 \mathrm{~K}$ ): (a) filled-states STM image, $65 \times 65$ $\AA^{2}$; and (b) scan of the height profile along the [1110] direction.

separated by $32 \AA$. A third trench should appear at $16 \AA$, point c, but instead, it is replaced by a mound that is $2.8 \pm 0.1 \AA$ higher than the gray spots at points $b$ and $d$. As noted earlier, the gray spots arise from the filled dangling bonds of the secondlayer arsenic atoms. A vertical distance of $2.8 \AA$ corresponds to the single-step height of $\mathrm{GaAs}(001)$. Therefore, we attribute the white mounds to $\mathrm{AsH}_{x}$ species adsorbed on the gallium dimers.

Presented in Figure 4 is the infrared reflectance spectrum of adsorbed arsine on the $(4 \times 2)$ reconstruction after an $1800-\mathrm{L}$ dose at $297 \mathrm{~K}$. The spectrum contains five discernible peaks at $2135,2100,2090,2050$, and $2020 \mathrm{~cm}^{-1}$, which are due to As-H stretching vibrations. ${ }^{6,8,9,28}$ The relatively intense band at 2135 $\mathrm{cm}^{-1}$ can be attributed to molecularly adsorbed arsine. Gasphase $\mathrm{AsH}_{3}$ exhibits asymmetric and symmetric stretching modes at 2123 and $2116 \mathrm{~cm}^{-1}$, respectively. ${ }^{31}$ Conversely, the peaks at lower frequency are most likely due to adsorbed $\mathrm{AsH}_{2}$ and AsH species. No infrared bands between 1900 and 1200 $\mathrm{cm}^{-1}$, which could be attributed to gallium-hydrogen bonds, are observed. Evidently, arsine dissociation is accompanied by hydrogen transfer to arsenic sites, not to gallium sites. ${ }^{17}$

3.2. Ab Initio Calculations of the Adsorbate Structures. Shown in Figure 5 are the optimized structures for molecularly and dissociatively adsorbed arsine. Initially, the molecule attaches to one of the dangling bonds on a gallium dimer, as indicated in cluster $\mathbf{1}$. The length of the dative bond between the As and Ga atoms (atoms numbered 1 and 2) is $2.76 \AA$. Next, the arsine molecule dissociates into an arsenic dihydrogen species, as shown in cluster 2 . This creates a covalent As-Ga bond with a length of $2.53 \AA$. In this reaction, the hydrogen

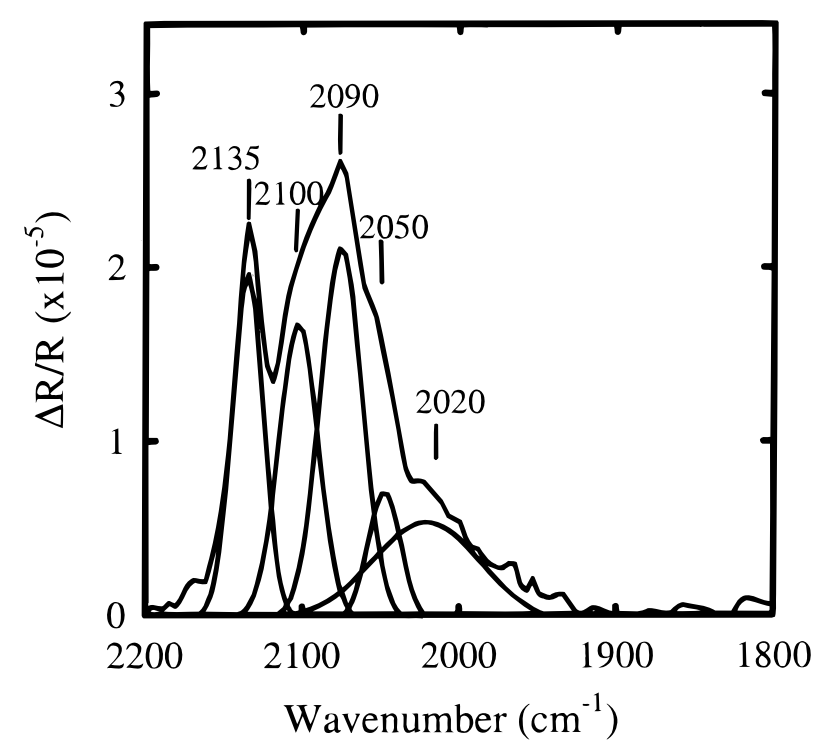

Figure 4. Infrared reflectance spectrum of adsorbed arsine on the $\mathrm{GaAs}(001)-(4 \times 2)$ surface at $297 \mathrm{~K}$.
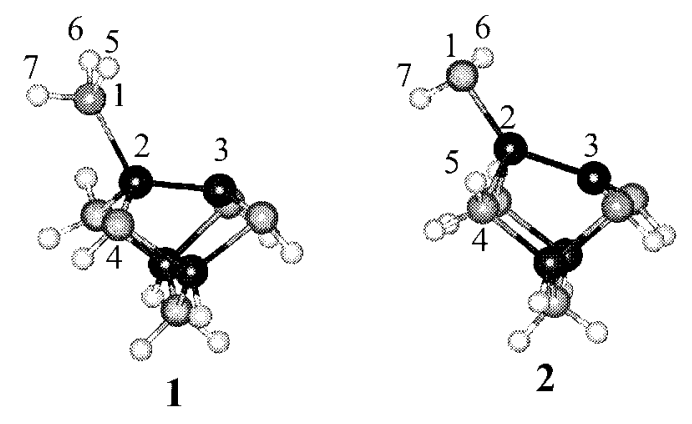

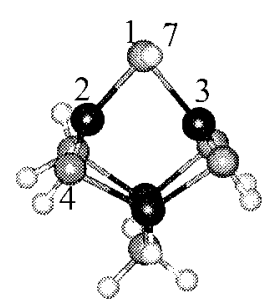

3

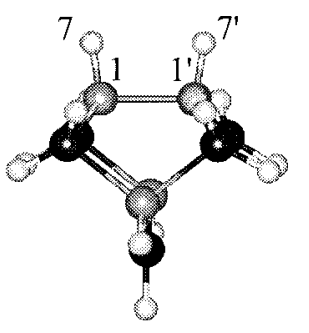

4
Figure 5. Ball-and-stick models of the optimized clusters, showing the surface species during dissociative adsorption of arsine: (1) $\mathrm{AsH}_{3}$, (2) $\mathrm{AsH}_{2}$, (3) AsH, and (4) coupled $\mathrm{AsH}$. The As, Ga, and $\mathrm{H}$ atoms are the large gray, large black, and small white spheres, respectively.

atom (no. 5) is transferred to a second-layer arsenic atom (no. 4). Note that the gallium dimer buckles to achieve an $\mathrm{sp}^{3}$ geometry about the four-coordinate $\mathrm{Ga}$ atom (no. 2) and an $\mathrm{sp}^{2}$ geometry about the three-coordinate Ga atom (no. 3). The $\mathrm{AsH}_{2}$ species may dissociate into $\mathrm{AsH}$, thereby producing cluster $\mathbf{3}$. This reaction leads to insertion of the arsenic atom across the gallium dimer bond. It is also possible for two As-H groups to combine, forming a coupled arsenic monohydrogen structure, as shown in cluster 4 .

The vibrational modes predicted for each cluster compound are listed in Table 1. In addition, the table lists the frequencies and intensities of the infrared bands observed for arsine adsorption on the $(4 \times 2)$ surface at $297 \mathrm{~K}$. The calculated frequencies are given without the introduction of a scaling factor. Adsorbed $\mathrm{AsH}_{3}$ (cluster 1) exhibits two asymmetric stretches at 2162 and $2143 \mathrm{~cm}^{-1}$ and one symmetric stretch at $2103 \mathrm{~cm}^{-1}$. The peak at $2103 \mathrm{~cm}^{-1}$ is the most intense, while the peak at 
TABLE 1: Predicted and Observed Vibrational Modes for Arsine Adsorbed on the $(4 \times 2)$ Surface at $297 \mathrm{~K}$

\begin{tabular}{|c|c|c|c|c|c|}
\hline \multirow[b]{2}{*}{ assignment $^{a}$} & \multicolumn{3}{|c|}{ theory } & \multicolumn{2}{|c|}{ experiment } \\
\hline & $\begin{array}{l}\text { frequency } \\
\left(\mathrm{cm}^{-1}\right)\end{array}$ & intensity ${ }^{c}$ & cluster $^{b}$ & $\begin{array}{l}\text { frequency } \\
\left(\mathrm{cm}^{-1}\right)\end{array}$ & intensity $^{c}$ \\
\hline$\left(\mathrm{H}_{5} \mathrm{H}_{6} \mathrm{H}_{7}\right) \mathrm{As}_{1}, \mathrm{a}$ & 2162 & w & 1 & & \\
\hline$\left(\mathrm{H}_{5} \mathrm{H}_{6} \mathrm{H}_{7}\right) \mathrm{As}_{1}, \mathrm{a}$ & 2143 & $\mathrm{~m}$ & 1 & 2135 & $\mathrm{~m}$ \\
\hline $\mathrm{H}_{7}-\mathrm{As}_{1}-\mathrm{As}_{1^{\prime}}-\mathrm{H}_{7^{\prime}}, \mathrm{s}$ & 2118 & $\mathrm{~s}$ & 4 & 2100 & $\mathrm{~s}$ \\
\hline $\mathrm{H}_{7}-\mathrm{As}_{1}-\mathrm{As}_{1^{\prime}}-\mathrm{H}_{7^{\prime}}, \mathrm{a}$ & 2106 & w & 4 & & \\
\hline$\left(\mathrm{H}_{5} \mathrm{H}_{6} \mathrm{H}_{7}\right) \mathrm{As}_{1}, \mathrm{~s}$ & 2103 & $\mathrm{~s}$ & 1 & 2090 & s \\
\hline $\mathrm{H}_{6}-\mathrm{As}_{1}-\mathrm{H}_{7}, \mathrm{a}$ & 2060 & $\mathrm{~m}$ & 2 & 2050 & $\mathrm{~W}$ \\
\hline $\mathrm{H}_{6}-\mathrm{As}_{1}-\mathrm{H}_{7}, \mathrm{~s}$ & 2033 & $\mathrm{~m}$ & 2 & & \\
\hline $\mathrm{As}_{1}-\mathrm{H}_{7}$ & 2027 & $\mathrm{~m}$ & 3 & 2020 & $\mathrm{w}$ \\
\hline
\end{tabular}

$2162 \mathrm{~cm}^{-1}$ is the weakest. The experimentally observed bands at 2135 and $2090 \mathrm{~cm}^{-1}$ correspond closely to the theoretical modes at 2143 and $2103 \mathrm{~cm}^{-1}$ and, therefore, can be assigned to molecularly adsorbed arsine.

Adsorbed $\mathrm{AsH}_{2}$ (cluster 2) generates asymmetric and symmetric stretching modes at 2060 and $2033 \mathrm{~cm}^{-1}$, respectively. It should be pointed out that there is a pair of nonbonding $4 \mathrm{~s}$ electrons on the arsenic atom (no. 1, Figure 5), which screens the nucleus and causes the As $-\mathrm{H}$ vibrational frequencies to decrease. ${ }^{28}$ The experimentally observed bands at 2050 and 2020 $\mathrm{cm}^{-1}$ are a reasonably good match to the predicted $\mathrm{AsH}_{2}$ modes and can be assigned to this species. However, note that the stretching vibration for the arsenic monohydrogen bond in cluster 3 is $2027 \mathrm{~cm}^{-1}$, which is a good match to the observed band at $2020 \mathrm{~cm}^{-1}$ as well. Consequently, this low-frequency feature may result from either $\mathrm{AsH}_{2}$ or $\mathrm{AsH}$ adsorbed on the (4 $\times 2$ ) reconstruction. The coupled arsenic monohydrogen bond (cluster 4) exhibits an intense symmetric stretch at $2118 \mathrm{~cm}^{-1}$ and a weak asymmetric stretch at $2106 \mathrm{~cm}^{-1}$. The infrared band found at $2100 \mathrm{~cm}^{-1}$ can be assigned to the symmetric stretch of coupled $\mathrm{As}-\mathrm{H}$ on the semiconductor surface.

In summary, the infrared bands observed upon $\mathrm{AsH}_{3}$ adsorption on the $(4 \times 2)$ reconstruction can be assigned as follows: $\mathrm{AsH}_{3}, 2135$ and $2090 \mathrm{~cm}^{-1}$; coupled AsH, $2100 \mathrm{~cm}^{-1} ; \mathrm{AsH}_{2}$, 2050 and $2020 \mathrm{~cm}^{-1}$; and isolated $\mathrm{AsH}, 2020 \mathrm{~cm}^{-1}$. By comparing the intensities of these peaks, we can obtain an estimate of the relative coverages of each of the $\mathrm{AsH}_{x}$ species. To perform this calculation, the infrared spectrum (Figure 4) was deconvoluted into five Gaussian peaks using the curvefitting software supplied with the Digilab infrared spectrometer. Then, the integrated area of each peak was divided by its theoretical intensity, as obtained from the ab initio calculations. The theoretical intensity was calculated from the first derivative of the dipole moment. Finally, these normalized peak areas were divided by the sum of all of the peak areas and then multiplied by the total coverage of $0.046 \mathrm{ML}$, as measured by STM. This calculation yielded the following coverages after exposure to 5 $\times 10^{-7}$ torr of arsine at $297 \mathrm{~K}: 0.022 \mathrm{ML} \mathrm{AsH}_{3}, 0.012 \mathrm{ML}$ $\mathrm{AsH}_{2}$, and $0.012 \mathrm{ML} \mathrm{AsH}$. The uncertainty of this measurement is assumed to be $\pm 50 \%$.

3.3. Arsine Adsorption at Elevated Temperatures. Presented in Figure 6 is a series of infrared reflectance spectra taken after dosing $2000 \mathrm{~L}_{\text {of }} \mathrm{AsH}_{3}$ at temperatures between 297 and $574 \mathrm{~K}$. Note that larger dosages had no effect on the spectra. Inspection of the figure reveals that the intensities of the bands at 2135 and $2090 \mathrm{~cm}^{-1}$, which are due to adsorbed $\mathrm{AsH}_{3}$, gradually decline to zero as the temperature is raised from 297 to $454 \mathrm{~K}$. In contrast, the intensities of the peaks at 2100, 2020, and $2050 \mathrm{~cm}^{-1}$, due to $\mathrm{AsH}_{2}$ and $\mathrm{AsH}$, stay constant or even

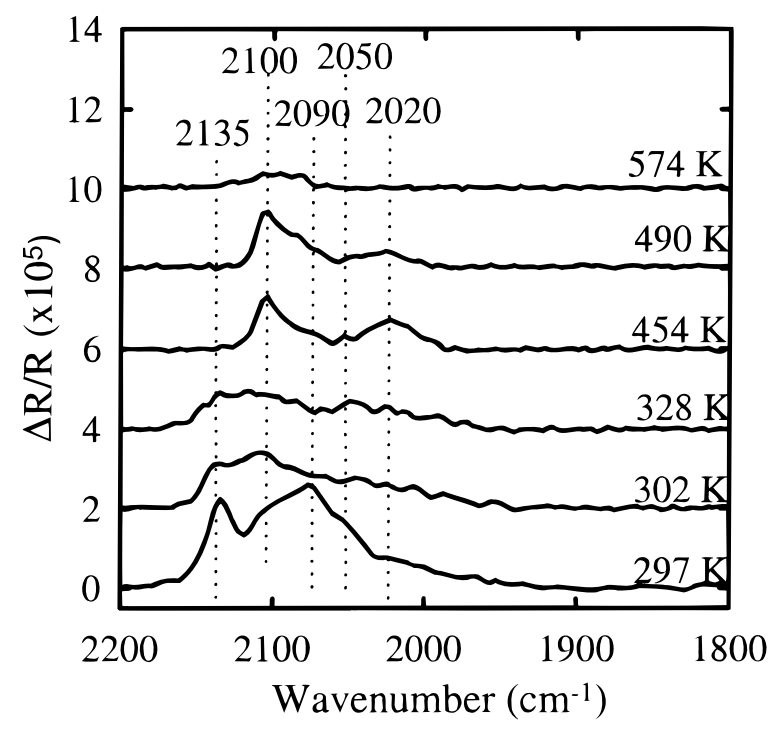

Figure 6. Infrared reflectance spectra of adsorbed arsine on the GaAs$(001)-(4 \times 2)$ surface at different temperatures.

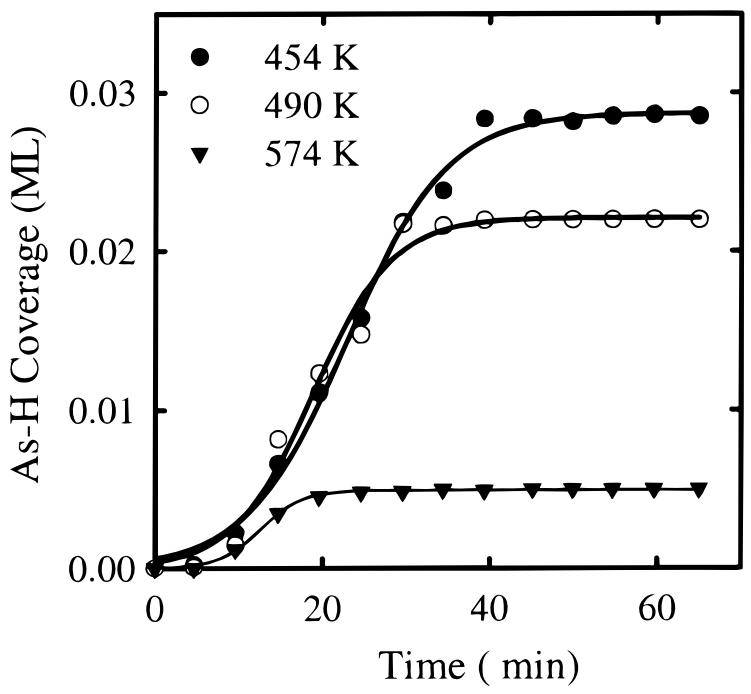

Figure 7. Dependence of the $\mathrm{As}-\mathrm{H}$ coverage on time and temperature during exposure of the $(4 \times 2)$ reconstruction to $5 \times 10^{-7}$ torr of arsine at $454-574 \mathrm{~K}$.

slightly increase as the temperature is raised to $454 \mathrm{~K}$. Then, these three peaks slowly disappear with further heating to 574 $\mathrm{K}$. The order in which the infrared bands decline in intensity during heating is consistent with their assignments, as $\mathrm{AsH}_{3}$ bonds much more weakly to the surface than either $\mathrm{AsH}_{2}$ or AsH.

In Figure 7, we present three arsine adsorption isotherms recorded between 454 and $574 \mathrm{~K}$. To construct these plots, a series of infrared spectra were collected during exposure to 5 $\times 10^{-7}$ torr of $\mathrm{AsH}_{3}$ at each temperature, and the integrated area under the bands was taken to be proportional to the concentration of arsenic monohydrogen species. As described above, no molecularly adsorbed arsine is present at these temperatures. Each of the curves exhibits a sigmoidal shape, in which the coverage increases slowly with time, then rapidly accelerates, and finally levels off. The steady-state coverage of arsenic-hydrogen species falls with increasing temperature, from 0.029 to 0.021 to $0.005 \mathrm{ML}$ at 454,490 , and $574 \mathrm{~K}$, respectively. The solid lines shown in the figure were obtained by fitting the data to a kinetic model, which is described below. 


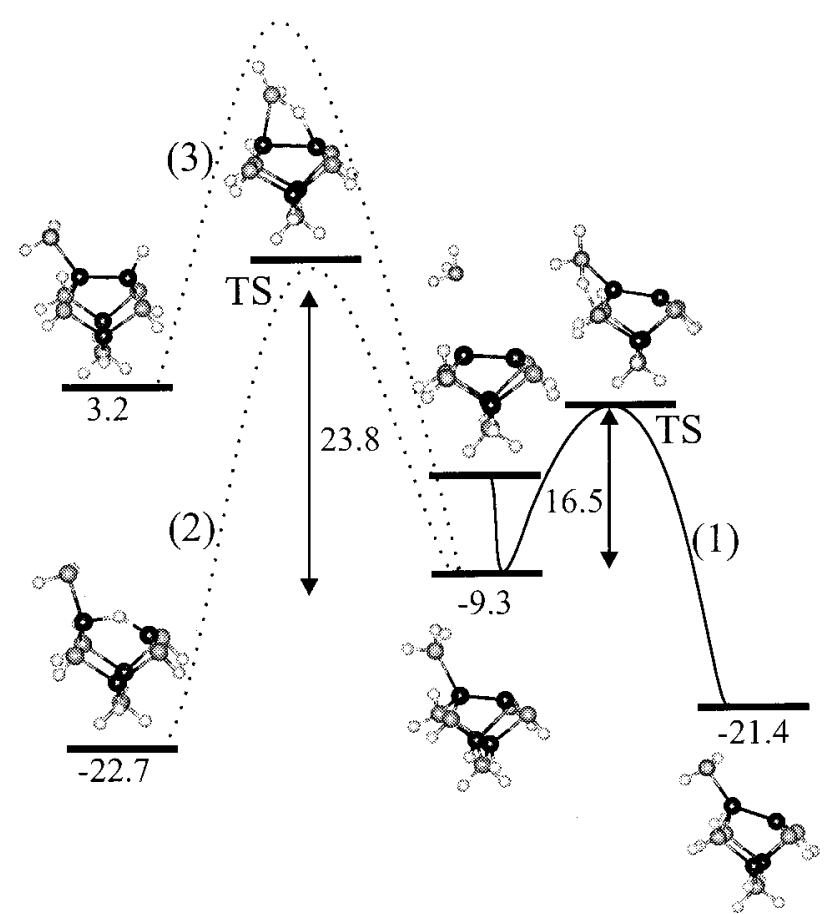

Figure 8. Potential energy diagram for arsine adsorption and dissociation into $\mathrm{AsH}_{2}$.

Although the As-H vibrational bands exhibit reduced intensity when $\mathrm{AsH}_{3}$ is dosed at $574 \mathrm{~K}, \mathrm{X}$-ray photoemission spectroscopy reveals that more arsenic is deposited on the surface at this temperature than at lower temperatures. The intensities of the infrared peaks for $\mathrm{AsH}_{2}$ and $\mathrm{AsH}$ decline because hydrogen, not arsenic, desorbs from the surface. The arsenic atoms that are left behind quickly combine to form arsenic dimers. We have found that As-rich $(2 \times 4)$ domains nucleate and grow on the $(4 \times 2)$ reconstruction during exposure to $>1.0 \times 10^{4} \mathrm{~L}_{3}$ of $\mathrm{AsH}_{3}$ at $574 \mathrm{~K}$.

3.4. Binding Energies of the Adsorbate Structures. Shown in Figure 8 is a potential energy diagram for arsine adsorption and decomposition on a gallium dimer. The binding energy $\left(\Delta E_{\mathrm{B}}^{298}\right)$ of each stable species is calculated relative to the isolated $\mathrm{Ga}_{4} \mathrm{As}_{5} \mathrm{H}_{9}$ cluster and arsine molecule and is defined as

$$
\Delta E_{\mathrm{B}}^{298}=E_{(\text {product })}^{298}-E_{\left(\mathrm{Ga}_{4} \mathrm{As}_{5} \mathrm{H}_{9}\right)}^{298}-E_{\left(\mathrm{AsH}_{3}\right)}^{298}+\mathrm{ZPE}
$$

The zero-point-energy (ZPE) correction accounts for the effects of molecular vibrations, which persist even at $0 \mathrm{~K}$. All other terms on the right-hand side of eq 1 include a thermal energy correction, which adds the contributions of molecular rotation, vibration, and translation at $298 \mathrm{~K}$ and $1 \mathrm{~atm}$ into the total energy. ${ }^{32}$

As can be seen in the middle of the diagram in Figure 8, the arsine molecule datively bonds to one of the empty dangling bonds on the gallium dimer, releasing $-9.3 \mathrm{kcal} / \mathrm{mol}$ of energy. To transform the dative bond into a covalent bond, one hydrogen atom must be released from the arsine molecule to a nearby adsorption site. There are three possible routes through which this can occur: (1) transfer of the $\mathrm{H}$ atom to a second-layer As atom; (2) insertion of the $\mathrm{H}$ atom into the $\mathrm{Ga}$ dimer bond; and (3) transfer of the $\mathrm{H}$ atom to the other Ga dangling bond. In the first case, an energy barrier of $16.5 \mathrm{kcal} / \mathrm{mol}$ must be overcome to produce an $\mathrm{AsH}_{2}$ species with an overall binding energy of $-21.4 \mathrm{kcal} / \mathrm{mol}$. The transition state was calculated using the synchronous transit-guided quasi-Newton method (STQN). ${ }^{33}$ Only one imaginary frequency was found in the DFT calculation. A normal-mode analysis reveals that this imaginary frequency is associated with hydrogen transfer and that the trajectory of the H-atom movement is from arsine to the secondlayer arsenic atom.

Conversely, if the hydrogen atom inserts into the $\mathrm{Ga}-\mathrm{Ga}$ dimer bond, as in the second pathway, then a cluster with a binding energy of $-22.7 \mathrm{kcal} / \mathrm{mol}$ is produced. This structure is slightly more stable than the one with only As $-\mathrm{H}$ bonds. However, the energy barrier for this reaction is $23.8 \mathrm{kcal} / \mathrm{mol}$. Assuming reactions 1 and 2 have the same preexponential factor for the Arrhenius relationship, the reaction that preserves the number of As $-\mathrm{H}$ bonds will be $2.2 \times 10^{5}$ times faster at 297 $\mathrm{K}$ than the reaction that generates a bridging $\mathrm{Ga}-\mathrm{H}-\mathrm{Ga}$ bond.

The difference in activation energy between the two reaction pathways described above is $7.0 \mathrm{kcal} / \mathrm{mol}$. This value is substantially larger than the uncertainty associated with the DFT method. For example, the transition state for ammonia decomposition on $\mathrm{Si}(100)-(2 \times 1)$ has been calculated by Musgrave and co-workers using DFT and the more accurate QCISD(T) (quadratic configuration interaction, single and double excitations, with the triple correction). ${ }^{34}$ They found that the energy difference between the two methods was only $2.5 \mathrm{kcal} / \mathrm{mol}$. Therefore, the calculations provide solid evidence for hydrogen transfer to arsenic sites.

We have attempted to find a stable cluster with hydrogen transfer to the terminal gallium site, as shown in reaction 3 . However, the calculation fails to converge, because this cluster lackstwo electrons, which requires that one of the arsenic dangling bonds be empty. To remedy this situation, we artificially added two electrons and generated a negatively charged cluster $\left(\mathrm{C}^{2-}\right)$ with a binding energy of $-32.0 \mathrm{kcal} / \mathrm{mol}$. The energy contribution from the two additional electrons must be subtracted from this value. This energy term is the electron affinity $(A): A=E\left(\mathrm{M}^{1-}\right)-E\left(\mathrm{M}^{0}\right) .{ }^{32}$ To obtain this energy, ab initio calculations were performed on the $\mathrm{AsH}_{2}{ }^{0}$ and $\mathrm{AsH}_{2}{ }^{1-}$ molecules, and $A$ was taken to equal the difference in binding energies between the two stable states, which is $-17.6 \mathrm{kcal} /$ mol. Therefore, the approximate binding energy of the neutral cluster is $-32.0-2(-17.6)=3.2 \mathrm{kcal} / \mathrm{mol}$. This value is much higher than that of the reactants, and so this reaction is unlikely to occur.

In summary, of the three pathways examined for arsine dissociation, the one that has the lowest transition-state energy and generates products more stable than the reactants is the reaction that transfers the hydrogen atom to the second-layer arsenic site. This result is consistent with our infrared spectra for adsorbed arsine, which do not contain any vibrational bands for gallium hydrides. It should be noted that this result contradicts an earlier study of arsine decomposition by White and co-workers. ${ }^{15}$ These authors observed a $\mathrm{Ga}-\mathrm{H}$ band at 1870 $\mathrm{cm}^{-1}$ in a HREELS spectrum collected during arsine dosing. We attribute this observation to the presence of hot filaments in their vacuum chamber, which dissociated some of the arsine molecules and caused $\mathrm{H}$ atoms from the gas to adsorb onto exposed gallium sites (see experimental section).

In Figure 9 are listed the binding energies for further decomposition of $\mathrm{AsH}_{2}$ into $\mathrm{AsH}$ and an As dimer (from left to right in the diagram). In these reactions, hydrogen molecules desorb from the cluster, and the energy of $\mathrm{H}_{2}$ bond is included in the calculation (eq 1). The formation of $\mathrm{AsH}$ from $\mathrm{AsH}_{2}$ proceeds with insertion of the arsenic atom between the gallium dimer atoms, generating one additional $\mathrm{Ga}-\mathrm{As}$ bond. This 


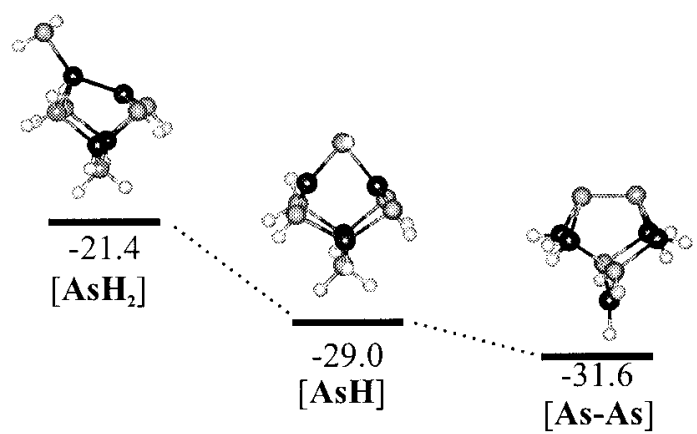

Figure 9. Potential energy diagram for the decomposition of $\mathrm{AsH}_{2}$ into $\mathrm{AsH}$ and an As dimer.

lowers the potential energy of the system by $7.6 \mathrm{kcal} / \mathrm{mol}$. Next, two of the adsorbed AsH species react with one another, desorb an $\mathrm{H}_{2}$ molecule, and produce an arsenic dimer. This is illustrated by the cluster furthest to the right in Figure 9. The potential energy of the cluster with the As dimer is lowered by an additional $2.6 \mathrm{kcal} / \mathrm{mol}$ relative to that of the cluster with AsH. Thus, the cluster calculations indicate that the complete decomposition of adsorbed arsine into arsenic is a thermodynamically favored process.

\section{Discussion}

4.1. Adsorption States. On the basis of our results, the adsorption of arsine on the $(4 \times 2)$ surface can be summarized as follows. Arsine adsorbs molecularly onto a gallium dimer to form a weakly bonded state with a binding energy of $-9.3 \mathrm{kcal} /$ mol. This species exhibits infrared bands at 2135 and $2090 \mathrm{~cm}^{-1}$. At $297 \mathrm{~K}$, half of the adsorbate resides in this state, while the remainder is composed of $\mathrm{AsH}_{2}$ and AsH species. The latter two intermediates have binding energies of -21.4 and -29.0 $\mathrm{kcal} / \mathrm{mol}$, respectively. They can be distinguished from one another by their vibrational modes at 2050 and $2100 \mathrm{~cm}^{-1}$, respectively. The observation of both molecular and dissociative channels during arsine adsorption at $297-574 \mathrm{~K}$ is consistent with previous studies. ${ }^{14,15,17}$

The theoretical binding energy of $-9.3 \mathrm{kcal} / \mathrm{mol}$ for the molecularly adsorbed state agrees with measurements of the arsine desorption energy by temperature-programmed desorption. ${ }^{14}$ In that study, an activation energy of $10-12 \mathrm{kcal} / \mathrm{mol}$ was recorded. In addition, the arsine binding energy falls within the range observed for As-Ga dative bonds. For example, bond energies for trimethylarsine-trimethlygallium and arsinegallane are 10 and $16 \mathrm{kcal} / \mathrm{mol}$, respectively. ${ }^{35,36}$ Our value is also in agreement with a molecular beam study of tertiarybutylarsine adsorption on a gallium-rich $\mathrm{GaAs}(001)$ surface. ${ }^{37}$ Because the activation energy for arsine desorption is much lower than that for arsine dissociation (9.3 versus $16.5 \mathrm{kcal} /$ mol), most of the $\mathrm{AsH}_{3}$ molecules will desorb back into the gas phase at elevated temperature, instead of decomposing into adsorbed arsenic.

Once arsine dissociates into $\mathrm{AsH}_{2}$, its further decomposition into $\mathrm{AsH}$ and an arsenic dimer occurs through the desorption of hydrogen from the surface. Several studies have determined that the energy barrier for hydrogen desorption is $14 \pm 2 \mathrm{kcal} /$ mol. ${ }^{17,38,39}$ Therefore, the removal of the first hydrogen atom from adsorbed arsine is most likely the slowest step among the three sequential dissociation reactions.

4.2. Decomposition Kinetics. We propose the following mechanism for arsine adsorption and decomposition on the $\operatorname{GaAs}(001)-(4 \times 2)$ surface.

$$
\begin{gathered}
\mathrm{AsH}_{3(\mathrm{~g})}+*_{\mathrm{Ga}} \underset{k_{\mathrm{d}}}{k_{\mathrm{a}}} *_{\mathrm{Ga}}\left(\mathrm{AsH}_{3}\right) \\
*_{\mathrm{As}}+*_{\mathrm{Ga}}\left(\mathrm{AsH}_{3}\right) \stackrel{k_{\mathrm{f} 1}}{\longrightarrow} *_{\mathrm{As}}(\mathrm{H})+*_{\mathrm{Ga}}\left(\mathrm{AsH}_{2}\right) \\
*_{\mathrm{As}}(\mathrm{H})+*_{\mathrm{Ga}}\left(\mathrm{AsH}_{2}\right) \stackrel{k_{\mathrm{f2}}}{\longrightarrow} *_{\mathrm{As}}+*_{\mathrm{Ga}}(\mathrm{AsH})+\mathrm{H}_{2} \\
2 *_{\mathrm{Ga}}(\mathrm{AsH}) \stackrel{k_{\mathrm{s}}}{\longrightarrow} 2 *_{\mathrm{As}}+\mathrm{H}_{2}
\end{gathered}
$$

where $*_{\mathrm{Ga}}$ and $*_{\mathrm{As}}$ are the gallium and arsenic adsorption sites and the subscript ( $\mathrm{g}$ ) refers to the gas phase. Overall, this reaction converts one Ga site into one As site.

$$
\mathrm{AsH}_{3(\mathrm{~g})}+*_{\mathrm{Ga}} \rightarrow *_{\mathrm{As}}+{ }^{3} /{ }_{2} \mathrm{H}_{2}
$$

To simplify the kinetics, one can combine reactions 3 and 4 to obtain a single surface reaction rate. Then, the rates of arsine adsorption $\left(r_{\mathrm{a}}\right)$, arsine desorption $\left(r_{\mathrm{d}}\right)$, arsine surface reaction $\left(r_{\mathrm{f}}\right)$, and hydrogen desorption $\left(r_{\mathrm{s}}\right)$ are expressed by

$$
\begin{gathered}
r_{\mathrm{a}}=k_{\mathrm{a}}[\mathrm{M}](1-\theta-\phi)=\frac{1}{4} \bar{v} S_{0}[\mathrm{M}](1-\theta-\phi) \\
r_{\mathrm{d}}=k_{\mathrm{d}}[\mathrm{D}] \phi \\
r_{\mathrm{f}}=k_{\mathrm{f}}[\mathrm{D}] \phi \theta \\
r_{\mathrm{s}}=k_{\mathrm{s}}[\mathrm{D}] \theta^{2}
\end{gathered}
$$

Here, $[\mathrm{M}]$ is the arsine concentration in the gas (molecules/ $\left.\mathrm{cm}^{3}\right) ; v$ is the mean molecular velocity of arsine $(\mathrm{cm} / \mathrm{s}) ; S_{0}$ is the initial sticking probability of arsine; [D] is the density of adsorption sites, equal to $6.26 \times 10^{14}\left(\mathrm{sites} / \mathrm{cm}^{2}\right)$; and $\phi$ and $\theta$ are the fractional coverages of $\mathrm{AsH}_{3}$ and $\mathrm{AsH}_{x}$ species $(x=1$, $2)$, respectively. The term $(1-\theta-\phi)$ corresponds to the fractional coverage of gallium sites. In eq 9, it is assumed that the surface reaction rate is proportional to the coverage of adsorbed $\mathrm{AsH}_{3}$ and $\mathrm{AsH}_{x}$ intermediates. By including the latter term, we can account for the acceleration of the rate of arsine adsorption with time (cf. Figure 7). Moreover, all of the $\mathrm{AsH}_{x}$ species are converted into adsorbed arsenic, and arsenic sites are required for reaction 3 to proceed. Note that, in eq 10, it is assumed that the hydrogen desorption rate is second-order in the $\mathrm{AsH}_{x}$ coverage.

Mass balances for the molecularly and dissociatively adsorbed species are as follows:

$$
\begin{gathered}
{[\mathrm{D}] \frac{\mathrm{d} \phi}{\mathrm{d} t}=r_{\mathrm{a}}-r_{\mathrm{d}}-r_{\mathrm{f}}=k_{\mathrm{a}}[\mathrm{M}](1-\theta-\phi)-} \\
k_{\mathrm{d}}[\mathrm{D}] \phi-k_{\mathrm{f}}[\mathrm{D}] \phi \theta \\
{[\mathrm{D}] \frac{\mathrm{d} \theta}{\mathrm{d} t}=r_{\mathrm{f}}-r_{\mathrm{s}}=k_{\mathrm{f}}[\mathrm{D}] \phi \theta-k_{\mathrm{s}}[\mathrm{D}] \theta^{2}}
\end{gathered}
$$

At temperatures above $450 \mathrm{~K}$, the adsorbed arsine can be treated as a steady-state species, which yields

$$
\phi=\frac{k_{\mathrm{a}}[\mathrm{M}](1-\theta)}{k_{\mathrm{a}}[\mathrm{M}]+\left(k_{\mathrm{d}}+k_{\mathrm{f}} \theta\right)[\mathrm{D}]}
$$

and because $k_{\mathrm{d}}[\mathrm{D}] \gg k_{\mathrm{a}}[\mathrm{M}]+k_{\mathrm{f}}[\mathrm{D}] \theta$, eq 13 can be simplified to

$$
\phi=\frac{k_{\mathrm{a}}[\mathrm{M}]}{k_{\mathrm{d}}[\mathrm{D}]}(1-\theta)
$$




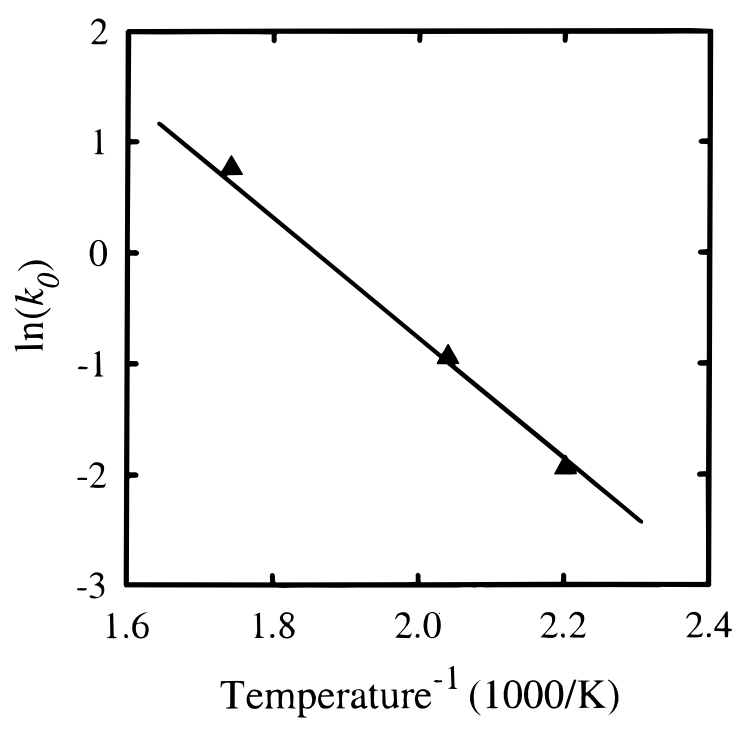

Figure 10. Dependence of the rate constant, $k_{0}$, on inverse temperature.

Substitution of eq 14 into eq 12 yields

$$
[\mathrm{D}] \frac{\mathrm{d} \theta}{\mathrm{d} t}=k_{0}[\mathrm{M}] \theta(1-\theta)-k_{\mathrm{s}}[\mathrm{D}] \theta^{2}
$$

where

$$
k_{0}=\frac{k_{\mathrm{f}} k_{\mathrm{a}}}{k_{\mathrm{d}}}=\frac{1}{4} \bar{v} S_{0} \frac{k_{\mathrm{f}}}{k_{\mathrm{d}}}
$$

Equation 15 can be integrated analytically, with the result that

$$
\theta(t)=\frac{\theta_{\mathrm{s}}}{1+e^{-k_{0}(t-\varphi)[\mathrm{M}] /[\mathrm{D}]}}
$$

in which $\theta_{\mathrm{s}}$ corresponds to the saturation coverage of $\mathrm{AsH}_{x}$ species and $\varphi$ is an integration constant.

The solid lines in Figure 7 are the best fit of eq 17 to the experimental data. Each curve provides a unique value of the rate constant $k_{0}$, which depends on temperature according to the Arrhenius relationship. A plot of the logarithm of the rate constant versus inverse temperature is shown in Figure 10. From this graph, we obtained an apparent activation energy $\left(E_{0}\right)$ and frequency factor $\left(A_{0}\right)$ of $11.6 \mathrm{kcal} / \mathrm{mol}$ and $5.7 \times 10^{4} \mathrm{~cm} / \mathrm{s}$, respectively. These data can be used to estimate the reactive sticking coefficient of arsine, $S_{\mathrm{R}}$, i.e., the fraction of impinging arsine that decomposes on the $(4 \times 2)$ surface. This coefficient is defined as

$$
S_{\mathrm{R}}=S_{0} \frac{k_{\mathrm{f}}}{k_{\mathrm{d}}}=\frac{4}{v} k_{0}
$$

The reactive sticking coefficient ranges from $3 \times 10^{-8}$ at $297 \mathrm{~K}$ to $3 \times 10^{-3}$ at $773 \mathrm{~K}$. Evidently, at temperatures used for MOVPE growth, only a small number of the impinging arsine molecules decompose into adsorbed arsenic on the gallium arsenide (001) surface. This is due to the fact that the rate of $\mathrm{AsH}_{3}$ desorption is much higher than that of $\mathrm{AsH}_{3}$ dissociation $\left(k_{\mathrm{d}} / k_{\mathrm{f}} \gg 1\right)$.

\section{Summary}

Arsine decomposes on the $\operatorname{GaAs}(001)-(4 \times 2)$ surface by first forming a dative bond with the gallium dimers and then undergoing sequential dissociation into $\mathrm{AsH}_{2}, \mathrm{AsH}$, and $\mathrm{As}$ dimers. Hydrogen atoms initially transfer to the arsenic sites, but eventually desorb as $\mathrm{H}_{2}$. The removal of the first $\mathrm{H}$ atom from $\mathrm{AsH}_{3}$ appears to be the slowest step in the reaction, with an estimated activation barrier of $16.5 \mathrm{kcal} / \mathrm{mol}$. Nevertheless, the rapid rate of $\mathrm{AsH}_{3}$ desorption limits the surface coverage, so that only a small fraction of the impinging molecules undergo decomposition.

Acknowledgment. Funding for this research was provided by the Office of Naval Research, Physical Sciences and Technology Division (N00014-95-1-0904) and by the National Science Foundation, Division of Materials Research (DMR9804719).

\section{References and Notes}

(1) Stringfellow, G. B. Organometallic Vapor-Phase Epitaxy, Theory and Practice; Academic Press: New York, 1989.

(2) Drathen, P.; Ranke, W.; Jacobi, K. Surf. Sci. 1978, 77, L162.

(3) Li, L.; Han, B. K.; Gan, S.; Qi, H.; Hicks, R. F. Surf. Sci. 1998, 398, 386.

(4) Pashley, M. D.; Haberern, K. W.; Gaines, J. M. Surf. Sci. 1992, 267, 153.

(5) Duke, C. B. Appl. Surf. Sci. 1993, 66, 543.

(6) Qi, H.; Gee, P. E.; Hicks, R. F. Phys. Rev. Lett. 1994, 72, 250.

(7) Northrup, J. E.; Froyen, S. Phys. Rev. B 1994, 50, 2015. Northrup, J. E.; Froyen, S. Phys. Rev. Lett. 1993, 71, 2276.

(8) Qi, H.; Gee, P. E.; Nguyen, T.; Hicks, R. F. Surf. Sci. 1995, 323,

(9) Hicks, R. F.; Qi, H.; Fu, Q.; Han, B.-K.; Li, L. J. Chem. Phys. 1999, 110, 10498.

(10) Gee, P. E.; Qi, H.; Hicks, R. F. Surf. Sci. 1995, 330, 135.

(11) Li, L.; Gan, S.; Han, B.-K.; Qi, H.; Hicks, R. F. Appl. Phys. Lett. 1998, 72, 951.

(12) Adamson, S. D.; Han, B. K.; Hicks, R. F. Appl. Phys. Lett. 1996, 69, 3236.

(13) Fu, Q.; Li, L.; Begarney, M. J.; Han, B.-K.; Law, D. C.; Hicks, R. F. J. Phys. IV (France) 1999, 9, 3.

(14) Bansenauer, B. A.; Creighton, J. R. Surf. Sci. 1992, 278, 317.

Wolf, M.; Zhu, X.-Y.; Huett, T.; White, J. M. Surf. Sci. 1992, 275 ,

(16) Zhu, X.; Wolf, M.; Huett, T.; Nail, J.; Bansenauer, B. A.; Creighton, J. R.; White, J. M. Appl. Phys. Lett. 1992, 60, 977.

(17) Qi, H.; Gee, P.E.; Hicks, R. F. Surf. Sci. 1996, 347, 289.

(18) Moll, N.; Kley, A.; Pehlke, E.; Scheffler, M. Phys. Rev. B 1996, 54,8844 .

(19) Schmidt, W. G. Appl. Phys. A 1997, 65, 581.

(20) Chadi, D. J. Phys. Rev. Lett. 1978, 41, 1062.

(21) Harrison, W. A. J. Vac. Sci. Technol. 1979, 16, 1492

(22) Pashley, M. D. Phys. Rev. B 1989, 40, 10481.

(23) Frisch, M. J.; Trucks, G. W.; Schlegel, H. B.; Scuseria, G. E.; Robb, M. A.; Cheeseman, J. R.; Zakrzewski, V. G.; Montgomery, J. A., Jr.; Stratmann, R. E.; Burant, J. C.; Dapprich, S.; Millam, J. M.; Daniels, A. D.; Kudin, K. N.; Strain, M. C.; Farkas, O.; Tomasi, J.; Barone, V.; Cossi, M.; Cammi, R.; Mennucci, B.; Pomelli, C.; Adamo, C.; Clifford, S.; Ochterski, J.; Petersson, G. A.; Ayala, P. Y.; Cui, Q.; Morokuma, K.; Malick, D. K.; Rabuck, A. D.; Raghavachari, K.; Foresman, J. B.; Cioslowski, J.; Ortiz, J. V.; Stefanov, B. B.; Liu, G.; Liashenko, A.; Piskorz, P.; Komaromi, I.; Gomperts, R.; Martin, R. L.; Fox, D. J.; Keith, T.; Al-Laham, M. A.; Peng, C. Y.; Nanayakkara, A.; Gonzalez, C.; Challacombe, M.; Gill, P. M. W.; Johnson, B. G.; Chen, W.; Wong, M. W.; Andres, J. L.; Head-Gordon, M.; Replogle, E. S.; Pople, J. A. Gaussian 98, revision A.6; Gaussian, Inc.: Pittsburgh, PA, 1998.

(24) Perdew, J. P.; Burke, K.; Wang, Y. Phys. Rev. B 1996, 54, 16533.

(25) Igel-Mann, G.; Stoll, H.; Preuss, H. Mol. Phys. 1988, 65, 1321.

(26) Bergner, A.; Dolg, M.; Kuechle, W.; Stoll, H.; Preuss, H. Mol. Phys. 1993, 80, 1431 .

(27) Dunning, T. H.; Hay, P. J. Modern Theoretical Chemistry; Plenum Press: New York, 1976; Vol. 3, p 1.

(28) Fu, Q.; Li, L.; Hicks, R. F. Phys. Rev. B 2000, 61, 11034.

(29) Biegelsen, D. K.; Bringans, R. D.; Northrup, J. E.; Swartz, L. E. Phys. Rev. B 1990, 41, 5701.

(30) Xue, Q. K.; Hashizume, T.; Zhou, J. M.; Sakata, T.; Sakurai, T.; Ohno, T. Phys. Rev. Lett. 1995, 74, 3177.

(31) Nishizawa, J.; Kurabayashi, T. J. Electrochem. Soc. 1983, 130, 413.

(32) Foresman, J. B.; Frisch, M. J. Exploring Chemistry with Electronic Structure Methods, 2nd ed.; Gaussian Inc.: Pittsburgh, PA. 1996; p 142. 
(33) Peng, C.; Ayala, P. Y.; Schlegel, H. B.; Frisch, M. J. J. Comput. Chem. 1996, 17, 49.

(34) Widjaja, Y.; Mysinger, M. M.; Musgrave, C. B. J. Phys. Chem. B 2000, 104, 2527.

(35) Moss, R. J. J. Cryst. Growth 1984, 68, 78.
(36) Dobbs, K. D.; Trachtman, M.; Bock, C. W.; Cowley, A. H. J. Phys. Chem. 1990, 94, 5210.

(37) Cui, J.; Ozeki, M.; Ohashi, M. Appl. Phys. Lett. 1997, 70, 502.

(38) Mokwa, W.; Kohl, D.; Heiland, G. Phys. Rev. B 1984, 29, 6709.

(39) Creighton, J. R. J. Vac. Sci. Technol. A 1990, 8, 3984. 